6th International Conference on Industrial Engineering and Industrial Management.

XVI Congreso de Ingeniería de Organización. Vigo, July 18-20, 2012

\title{
A Proposed Collaborative Network Enterprise Model in the Fruit-and-Vegetable Sector Using Maturity Models
}

\author{
Alonso Manzanedo M, De-la-Fuente Aragon MV ${ }^{1}$, Ros McDonnell L
}

\begin{abstract}
Spain is the first European producer and exporter of fresh fruits and vegetables. SMEs need to join forces, through collaboration, to make a continuous innovative effort to add value to the sector and face foreign competition. A collaborative network is the way for companies to share abilities and resources, processes and technology. This paper presents the development of a logistic network model, for the fruit-and vegetable companies, based on maturity models. This approach will allow evaluating, in an objective way, the state of the companies and the network from the views of the selected maturity models, the purpose of which is to establish the level of integration and collaboration within the studied network, and to propose evolutionary improvements in the network's collaborative processes.
\end{abstract}

Keywords: Fruit-and-Vegetable products, Cold Supply Chain, Collaborative Networks, Maturity Models

\subsection{Introduction}

Within the last thirty years the Fruit-and-Vegetable sector has become the first Spanish agricultural sector in terms of production value. Spain is the first European producer of fresh fruit and vegetables and the first European exporter of these products.

In an ever-increasing globalized market, with competition from producers and distributors from other regions within and outside of the European Union, companies are compelled to a continuous innovative effort to adopt and adapt new

\footnotetext{
${ }^{1} \mathrm{M}^{\mathrm{a}}$ Victoria de-la-Fuente Aragon $(\square)$ Grupo Gestión e Ingeniería de Organización (GIO). ETSII, Campus Muralla del Mar, C/ Dr. Fleming, s/n, 30202 Cartagena, Spain e-mail: marivi.fuente@upct.es
} 
measures to add value to the sector, making it possible to respond to consumers' demands and to face fierce foreign competition.

The importance of focusing on those aspects which enable producers to have an advantageous position over their competitors gives rise to the need for an evaluation of the performance of the Fruit-and-Vegetable companies, both as individual actors and within their own collaborative activities. To do so, maturity models are proposed to evaluate, by means of objective measuring, the current state of the company's individual and collaborative processes. Implementation of these models will help to improve the logistic network's performance.

This paper is organized as follows: Section 2 presents a review of the existing literature on inter-company collaborative networks and maturity models; Section 3 exhibits the theoretical framework used to develop a research project to create a logistic network model for the Fruit-and-Vegetable sector, from the point of view of key processes. After outlining the conclusions, the paper is concluded by suggesting directions for future research.

\subsection{A Review of the Literature}

\subsubsection{Key Features of the Cold Chain}

Within the concept of supply chain, the Cold Supply Chain stands out as a singularity. Due to the very nature of the products being processed, handled, transported and marketed, the management of this kind of chain is affected by a number of peculiar aspects. The integrity of these products must be preserved at all times during the phases of loading, transport, unloading, handling and storage, and the responsibility reaches as far as the retail selling point. To assure quality, food safety and shelf life of perishable produce, temperature control is essential all along this chain (Moureh et al., 2009).

The principles and general provisions on food legislation laid down by Regulation (EC) No 178/2002 of the European Parliament and of the Council of 28 January 2002 seek to guarantee food safety and to protect consumers' interests. To this goal, it is necessary to know and register all actions taken on a product from the start to the end of its supply chain. This is known as Product Traceability.

Traceability is about systematically linking information flows with physical flows of goods in a way that information on any specific batch or group of products can be recalled at any given time. Therefore, integrating information systems along the cold chain is crucial to achieve optimum levels of traceability and for comprehensive process management (Somers \& Nelson, 2003), as well as for inter-operativeness of key processes in the supply chain. 
Small and medium-sized companies with limited resources need to join forces, through collaboration, to adapt to ever-changing conditions in today's turbulent, competitive markets. They must improve significantly their abilities by means of new business models, strategies, governance rules, processes and technology (Camarinha-Matos et al., 2009).

Alliances and collaboration among members of the supply chain lead to an improved performance of the logistic network, increased inventory turnover, higher income, cost reduction, product availability and added value (Fawcett et al., 2008); all of which translates into competitive advantage against competitors (Dacin et al., 1997; Wheelen \& Hungar, 2000). For manufacturing companies sharing abilities and resources, collaboration is a key asset to obtain a quick response to market demands (Camarinha-Matos et al., 2009).

To build these collaborative links, member companies must be willing to invest in personnel and resources, even if other companies may benefit directly from their investment. They must also be prepared to share knowledge, either explicit or implicit, with other companies, even if these collaborators could be regarded as competitors (Dyer, 2000). Elmuti and Kathawala (2001) pointed out that trust is the hardest and the most important factor for the success of this kind of collaboration, since it is the people who trust each other, not the companies.

A collaborative network or collaborative supply chain is the optimum, most advanced level of collaborative relationship to be found among companies. These companies start by exchanging information. At any given stage, they decide to align some of their processes to achieve shared targets. Gradually, confidence is built among people, and in time this results in stronger collaborative relationships among companies, where efforts are pooled seeking common goals by sharing not only information, but also resources, risks, profit and loss (Camarinha-Matos \& Afsarmanesh, 2008).

\subsubsection{The Evolution of Maturity Models}

Maturity models are management tools. They are used to evaluate by means of objective measuring the current state of the company, depending on the views of each model. Its implementation will help to improve the company's internal and external processes. Possible improvements suggested by maturity models are arranged in steps in accordance with each level of maturity, the objective being an evolutionary improvement in processes.

The concept of maturity has become popular with the development of the Capability Maturity Model (CMM) proposed by Software Engineering Institute (SEI, 1995).

The concept of maturity processes has been developed and tested in software development processes (Harter et al., 2000), in project management processes (Ibbs \& Kwak, 2000), and in business processes (Fisher, 2004; Lee et al., 2007; 
McCormack, 2007; Vom Brocke \& Rosemann, 2010). Particular to the latter are those models specifically developed for supply chains (Lockamy \& McCormack, 2004; Daozhi et al., 2006).

Business Process Maturity stems from the idea that all processes have a life cycle, or stages of development, which are clearly definable, measurable and manageable in time. This evolves into the concept of maturity levels. Among all the Business Process Maturity Models (BPMM) found in literature, we pledge to the model proposed by (McCormack \& Johnson, 2001; McCormack, 2007), which analyzes the maturity of the company's processes from the following perspectives: definition of activities and processes documentation; job structuring; process management and measuring; management structure and process focusing.

The Supply Chain Maturity Model (SCMM) of Lockamy and McCormack (2004) expands the previously mentioned BPMM model to gauge the level of managerial integration, collaboration and trust currently existing among the members of the supply chain. The frame of reference used for the development and measuring of processes performance is the SCOR model. Five key processes are analyzed from the perspectives of McCormack's (2007) BPMM: plan, source, make, deliver and return.

None of the current models found in the literature can be used for measuring the maturity of collaborative networks, since they need to measure not only the factors necessary to evaluate processes or supply chains but also all the factors regarded in the literature as relevant for collaboration relationships (Verdecho et al., 2012), as shown in Table 1.

Table 1.1 Relevant factors in collaborative relationships (adapted from Verdecho et al., 2012)

\begin{tabular}{ll}
\hline Factors & \\
\hline Strategic factors & $\begin{array}{l}\text { Joint vision, design of the inter-enterprise network, equity, } \\
\text { top management support }\end{array}$ \\
$\begin{array}{l}\text { Business process and } \\
\text { infrastructure factors }\end{array}$ & $\begin{array}{l}\text { Process alignment, IS/ICTs interoperability, complementary } \\
\text { skills, coordination between activities }\end{array}$ \\
$\begin{array}{l}\text { Organizational } \\
\text { structure factors }\end{array}$ & $\begin{array}{l}\text { Collaboration leadership, compatibility of management } \\
\text { styles, joint decision-making, multidisciplinary teams }\end{array}$ \\
Cultural factors & $\begin{array}{l}\text { Trust, commitment, cooperation, information shared, } \\
\text { conflict resolution management }\end{array}$ \\
\hline
\end{tabular}

\subsection{Proposed Research}

A Fruit-and-Vegetable logistic network is composed of the following:

- Producers: farmers or agrarian associations dedicated to the production of fruits and vegetables, as well as to the packing operations necessary for subsequent marketing of their products. 
- Marketers: companies exporting these products and coordinating sales campaigns.

- Hauliers: companies committed to national and/or international transport of perishable goods.

- Distributors: acting as a customer in the collaborative network, these are mainly logistical platforms and large food chains.

The business model will be developed for a collaborative network of the Fruit and Vegetable sector by taking the SCOR model as a reference. The reason for choosing this model is the fact that it is easily extensible to any type of company, chain or network, besides being a model of reference thoroughly accepted by the academics. The processes of the network can be broken down on the basis of the five key processes proposed by the SCOR model (SCOR, 2010):

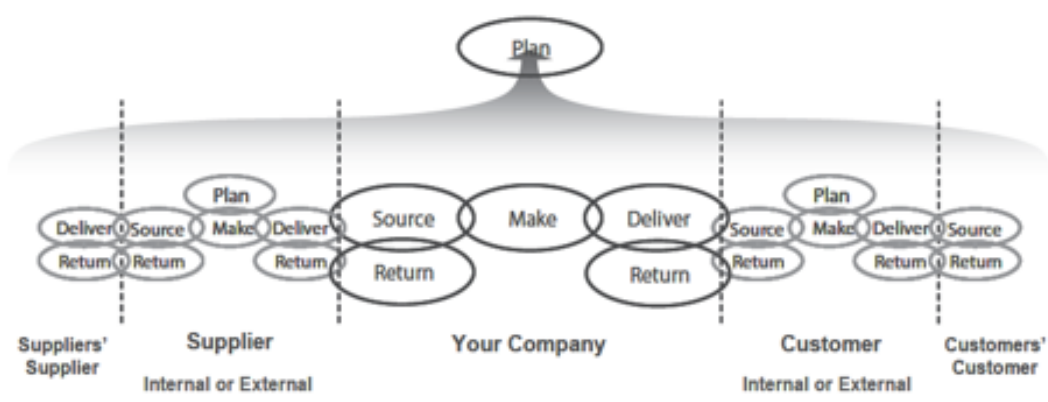

Fig. 1.1 Key Processes of the SCOR model, (SCOR, 2010)

Once the network's managerial model has been proposed it will be validated by using a repository of maturity models whose parameterization has been designed to analyze the singularities and the relevant factors of the processes of a collaborative network. The views used for the validation of the company model are:

- Functions: activities and documentation of each process will be analyzed (Fisher, 2004; Lee et al., 2006; McCormack, 2007).

- Assets: tangible and human resources will be analyzed (Fisher, 2004; Daozhi et al., 2006; Vom Brocke \& Rosemann, 2010)

- Management systems and IT systems: their degree of inter-connectability will be measured (Fisher, 2004; McCormack, 2007; Vom Brocke \& Rosemann, 2010).

- Costs: processes costs and supply chain management cost will be measured (Lockamy \& McCormack, 2004; Daozhi et al., 2006).

- Process structure: work teams integration, alliances, partnerships and contracts among members of the supply chain will be analyzed (Lee et al., 2007; McCormack, 2007). 
- Strategy: The decision-making process and strategy alignment will be analyzed (Fisher, 2004; Vom Brocke \& Rosemann, 2010).

- Culture: the organizational culture will be analyzed (Fisher, 2004; Vom Brocke \& Rosemann, 2010).

The maturity levels proposed (from the selected views) have been obtained after adapting the maturity levels of the models proposed by Fisher, 2004; Lockamy \& McCormack, 2004; McCormack, 2007; Pache \& Spalanzani, 2007; and Camarinha-Matos \& Afsarmanesh, 2008. These levels of maturity are:

- LEVEL 1. Ad hoc: The processes of the members of the supply chain are unstructured and directed towards the interests of their own organizations. They do not set objectives and are not capable of determining the results of the processes. For these reasons, the management costs of the supply chain are very high.

- LEVEL 2. Defined: The key processes of the network are defined and documented. Relationships consisting of mere information exchanges begin to appear among some members of the network, suppliers and customers. Monitoring tools start to be used for key processes.

- LEVEL 3. Linked: The management of the supply chain or network is a strategic function. Process managers define, develop and maintain the key processes. There is feedback between the key processes of the members (sharing objectives) and the measuring systems. Information is shared among the members. Partnership contracts exist among the members of the network. The network's management costs begin to decrease as customer satisfaction levels increase.

- LEVEL 4. Integrated: The members of the net collaborate at process level. Functions are organized and jobs are dimensioned under the guidelines of the SCM. Planning and forecasting tasks are performed jointly by the members of the network. The processes teams are responsible for the processes from start to end. Not only is information shared, but also resources for the attainment of compatible objectives. Contracts start to spread to all the members of the network. The costs of SCM decrease considerably and customers' satisfaction becomes a competitive advantage.

- LEVEL 5. Extended: There is reciprocal trust and mutual dependence among the members of the network, key variables for collaboration. Information, resources and responsibilities for the attainment of common objectives and generation of added value are shared, as well as risks, profits and losses.

Within these levels of maturity, the principles that should be implemented at each level in order to reach some superior results are described. The transition from one maturity level to another requires that several members of the network carry out organizational changes; changes in terms of cooperation modes, with processes interrelated or performance indicators adapted to the relationship patterns among the members. The scope of each one of these maturity levels upgrades the capacity of the processes of the supply network. 


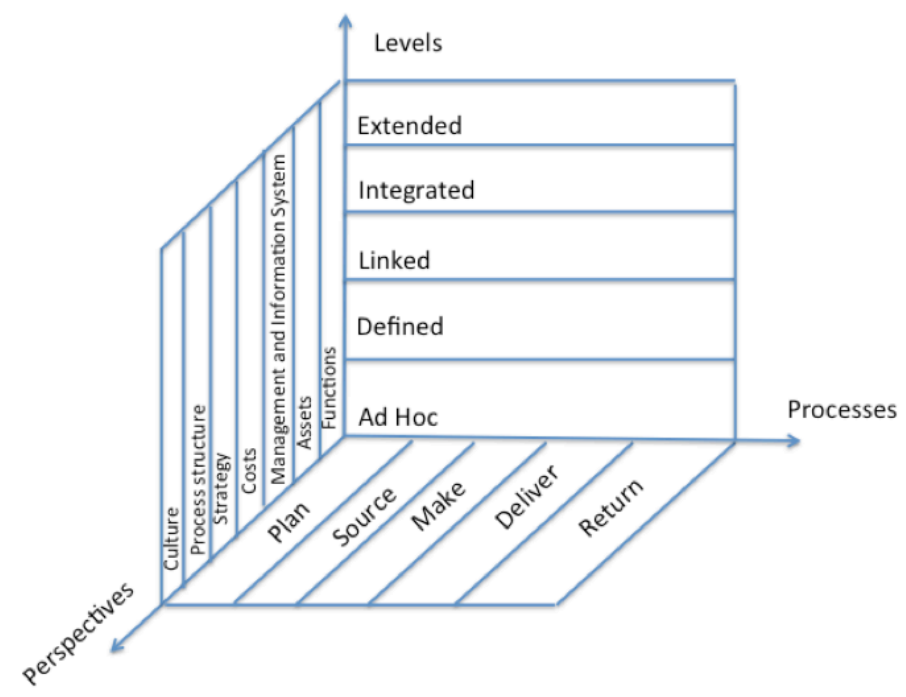

Fig. 1.2 Proposed Maturity Model

Based on the results obtained with the validation of the model, best practices will be proposed for the improvement of the collaborative network's performance.

\subsection{Conclusions}

Several methods exist for modelling business processes, depending on the various scenarios or organization views intended to be represented. In our research project we intend to develop a logistic network model for the Fruit and Vegetable sector based on maturity models.

The maturity models approach will allow evaluating in an objective way the state of the company and the network from the views determined by each of the selected models, the purpose of which is to establish the existing levels of integration and collaboration within the studied network, and to be able to obtain evolutionary improvements in the network's collaborative processes.

\subsection{References}

Camarinha- Matos LM, Afsarmanesh H (2008) Collaborative networks - Reference modelling. Springer, New York 
Camarinha- Matos LM, Afsarmanesh H, Galeano N, Molina A (2009) Collaborative networked organizations -Concepts and practice in manufacturing enterprises. Computers \&Industrial Engineering 57: 46-60

Dacin MT, Hitt MA, Levitas E (1997) Selecting partners for successful international alliances: examination of US and Korean firms. Journal of World Business 32 (1): 3-16

Daozhi Z, Liang Z, Xin L, Jianyong S (2006) A new supply chain maturity model with 3dimension perspective. International Technology and Innovation Conference1732-1737

Dyer JH (2000) Collaborative Advantage: winning through extended enterprise supplier networks. Oxford University Press

Elmuti D, Kathawala Y (2001) An overview of strategic alliances. Management Decision 39 (3): 205-217

Fawcett SE, Magnan GM, McCarter MW (2008) Benefits, barriers, and bridges to effective supply chain management. Supply Chain Management: An International Journal 13(1): 35-48

Fisher DM (2004) The Business Process Maturity Model. A practical approach for identifying opportunities for optimization, URL http://www.bptrends.com/resources_publications.cfm, accessed September 2005

Harter DE, Krishnan MS, Slaughter SA (2000) Effects of process maturity on quality, cycle time and effort in software product development. Management Science 46 (4): 451-66

Ibbs CW, Kwak YH (2000) Assessing Project management maturity. Project Management Journal 31(1): 32-43

Lee J, Lee D, Kang S (2007) An overview of the Business Process Maturity Model (BPMM). Springer, Berlin

Lockamy III A, McCormack K (2004) The development of a supply chain management process maturity model using the concepts of business process orientation. Supply Chain Management: An International Journal 9 (4):272-278

McCormack K (2007) Business Process Maturity: Theory and Application. DRK Research, Raleigh, $\mathrm{NC}$

McCormack K, Johnson W (2001) Business Process Orientation: Gaining the E-business Competitive Advantage, St Lucie Press, Delray Beach, FL

Moureh J, Tapsob S, Derens E, Flick D (2009) Air velocity characteristics within vented pallets loaded in a refrigerated vehicle with and without air ducts. International Journal of refrigeration 32:220-234

Pache G, Spalanzani A (2007) La gestion des chaînes logistiques multi-acteurs: perspectives stratégiques. Ed. PUG.

SCOR 2010. http://www.supply-chain.org

SEI 1995. http://www.sei.cmu.edu

Somers TM, Nelson KG, (2003) The impact of strategy and integration mechanisms on enterprise system value: empirical evidence from manufacturing firms. European Journal of Operational Research 146: 315-338

Verdecho MJ, Alfaro JJ, Rodriguez R, Ortiz A (2012) The analytic network process for managing inter-enterprise collaboration: A case study in a collaborative enterprise network. Expert Systems with Applications 39: 626-637

Vom Brocke J, Rosemann M (2010) Handbook in business process management 2.Springer

Wheelen TL, Hungar DJ, (2000) Strategic Management and Business Policy: Entering 21st Century Global Society. Prentice Hall, London. 